\title{
Characteristics and Outcomes of Dogs Admitted into Queensland RSPCA Shelters
}

\author{
Megan Hemy ${ }^{1, *,+}$ (D) Jacquie Rand ${ }^{1,2, \dagger}$, John Morton ${ }^{1,3}$ and Mandy Paterson ${ }^{1,4}$ \\ 1 School of Veterinary Science, The University of Queensland, Gatton, QLD 4343, Australia; \\ j.rand@uq.edu.au (J.R.); john.morton@optusnet.com.au (J.M.); mpaterson@rspcaqld.org.au (M.P.) \\ 2 Australian Pet Welfare Foundation, Kenmore, QLD 4069, Australia; jacquie@petwelfare.org.au \\ 3 Jemora Pty Ltd., Geelong, VIC 3220, Australia \\ 4 RSPCA, Wacol, QLD 4076, Australia \\ * Correspondence: mhemy1@gmail.com; Tel.: +614-39-850-717 \\ + These authors contributed equally to this work.
}

Received: 29 June 2017; Accepted: 25 August 2017; Published: 1 September 2017

Simple Summary: An up-to-date and comprehensive understanding of the characteristics and outcomes of dogs entering shelters is required for implementing targeted strategies to reduce euthanasia of healthy and treatable dogs in Australia. Currently, there are few up-to-date Australian data published on dogs entering shelters, and their outcomes. Of dogs entering the Royal Society for Prevention of Cruelty to Animals, Queensland shelters in 2014, the majority (58\%) were strays and $26 \%$ were puppies. Only $18 \%$ of dogs $>6$ months were desexed. Most dogs were reclaimed $(32 \%)$ or adopted $(43 \%)$. Strategies targeted to locations and breeds overrepresented by admissions are required to reduce shelter admissions, particularly of strays and unwanted litters.

\begin{abstract}
Over 200,000 stray and surrendered dogs are admitted to shelters and municipal facilities in Australia each year, and approximately $20 \%$ are euthanized. Contemporary, comprehensive data on the characteristics and outcomes of dogs entering shelters are required to reduce shelter admissions and euthanasia. However, there are currently limited up-to-date data published on dog admission into shelters. A retrospective single cohort study was conducted to describe the characteristics and outcomes of the dog population entering Royal Society for Prevention of Cruelty to Animals, Queensland (RSPCA-QLD) shelters in $2014(n=11,967)$. The majority of dog admissions were strays from the public $(24 \%)$ or from municipal councils (34\%). Just over a quarter of admissions were puppies, $18 \%$ of adults ( $>6$ months) were desexed, and the majority of admissions were crossbred dogs $(92 \%)$. The majority of owner surrenders $(86 \%)$ were due to human-related reasons. Most dogs were reclaimed $(32 \%)$ or adopted $(43 \%)$ and aggression was the most common reason for euthanasia of adult dogs $(45 \%)$. Low-cost or free desexing and identification programs targeted to areas and breeds contributing to high intake, and increased support services for owners at risk of surrendering their dog, should be trialed to determine their cost effectiveness in reducing shelter admissions and euthanasia.
\end{abstract}

Keywords: dog; shelter; RSPCA; Queensland; admission source; outcomes; characteristics; stray; surrendered; adopted; euthanized; microchip; identification; breed; desexed

\section{Introduction}

Over 200,000 stray and surrendered dogs are admitted to animal welfare shelters and local government animal facilities in Australia annually (9.3 dog admissions per 1000 residents), and 20\% are euthanized [1]. Approximately $38 \%$ of Australian households own a dog, and dogs constitute $36 \%$ of all animals received by the largest animal welfare organization in Australia, the Royal Society 
of Prevention of Cruelty to Animals (RSPCA) [2,3]. Almost 46,000 dogs were admitted to RSPCA animal shelters throughout Australia during the 2013/2014 financial year, which overlapped with data collection for this project (calendar year 2014). Of these, $36 \%$ were reclaimed, $37 \%$ were rehomed and almost $16 \%$ were euthanized [3]. Furthermore, over $27 \%$ of the 7300 dogs euthanized by the RSPCA in 2013/2014 were in RSPCA Queensland (RSPCA-QLD) shelters, which admitted 15,000 dogs during this period [3]. This represents 3.2 dogs admitted annually per 1000 residents in Queensland, which is almost double the 1.9 dogs admitted per 1000 residents nationally to RSPCA shelters $[3,4]$. The financial cost of this situation is evident. In the 2013/2014 financial year, RSPCA Queensland spent over $\$ 15$ million on its shelters, a $\$ 1.7$ million increase from the previous year due to an increase in sheltered animals $[5,6]$.

In addition to the financial costs, euthanasia of animals has detrimental effects on the psychological welfare of shelter workers [7-11]. Workers who are involved with euthanasia report experiencing stress, guilt and moral conflicts, increased levels of work-related stress, increased risk of substance abuse, and health problems [7-11]. Furthermore, shelter animals are also subjected to significant stresses, leading to illness, impaired psychological welfare and behavioral problems [12-15]. This can reduce the likelihood of successful adoption and increase the risk of euthanasia [12-15].

Despite the significance of these issues, there is little current information available on the profile of dogs entering shelters in Australia, the reasons and their outcomes. The most recent research which profiled dogs entering Australian shelters was published over ten years ago (2004) and focused on three Melbourne shelters [13]. It found that dogs in shelters were typically adult, small breed, stray males that were sexually entire, but there were considerable differences between each of the shelters $[13,16]$. Recently, a study profiling cats entering Australian RSPCA shelters identified risk factors for admission and euthanasia, and, based on this data, made recommendations for strategies to reduce the number of stray and surrendered cats in Australia [17]. This study demonstrated the value of comprehensive, up-to-date data on the population of cats in RSPCA shelters for guiding strategies to reduce shelter admissions and improve live release rates. A similar approach is warranted to better understand dog admissions and outcomes in shelters, so that more effective management strategies can be implemented. This is important because reducing shelter intake and increasing the number released alive, reduces the number of dogs euthanized [18,19].

The aims of this study were to describe the characteristics and outcomes of the dog population entering RSPCA-QLD shelters.

\section{Experimental Section}

\subsection{Data Collection and Study Design}

Data were sourced from the RSPCA's Sheltermate $\odot$ database and a retrospective single cohort study of all dogs entering Queensland RSPCA shelters in 2014 was conducted. Data obtained encompassed all first admissions of dogs from 1 January 2014 to 31 December 2014 into nine RSPCA-QLD shelters, and their associated outcomes from the nine shelters, adoption centers and associated pet shops. RSPCA-QLD operates four adoption centers where RSPCA animals can be adopted, but the full services of a shelter are not offered. The RSPCA also has contracts with selected pet shops to stock only RSPCA sheltered dogs and cats. Of the nine shelters, six had municipal council contracts and three did not accept strays from the general public (except under exceptional circumstances). Councils are local government bodies (similar to US counties) and are responsible for animal control and pound management. Pounds are council run facilities where stray, seized or surrendered dogs are kept for a set period of time until an owner comes forward or a dispute is resolved (e.g., licensing). If the dog remains unclaimed, it is transferred to a shelter facility (such as the RSPCA), rehomed or euthanized. Shelters are operated by welfare groups, and may or may not accept stray dogs, depending on government by-laws and shelter policies. Details of dogs accepted by 
the shelters were entered into the Sheltermate $\odot$ system. All dogs were scanned for a microchip on admission, and most were assessed by a veterinarian within 24 to $48 \mathrm{~h}$ of admission.

Raw data were imported from the RSPCA's Sheltermate $\odot$ program and the Australian Bureau of Statistics (ABS) Census 2011 population data, and were manipulated in Microsoft Excel. Further clarification on definitions of data categories and shelter procedures was obtained through verbal and email communication with RSPCA-QLD staff. Data categories obtained included RSPCA allocated animal identification number, primary breed, estimated mature size (small/medium/large/extra large), crossbred status (crossbred/purebred), source of admission, postcode of source, date of entry, date of birth, age group on admission (puppy/juvenile/young adult/mature adult/senior), reason for surrender (if applicable), sex, previously desexed (yes/no), outcome, date of outcome, reason for euthanasia (if applicable), and human population by postcode. For dogs with multiple admissions in 2014 (identified by their allocated shelter identification number), only data for their first admission were used in the analysis. For the purpose of this study, the terms "dog" and "dogs" refer to dogs collectively, regardless of age. Puppies are dogs $\leq 6$ months of age, whilst adults ( $>6$ months) include juveniles ( $>6$ months to 12 months), young adults ( $>12$ months to 2 years), mature adults ( $>2$ years to seven years) and senior adults ( $>7$ years). Allocation to age category was based on their estimated birth date, and where this was not recorded, the age category allocated by the RSPCA was used. If no history of desexing status was obtained on admission, desex status was allocated based on external signs of sterilization (e.g., ear tattoo, abdominal scar or absence of testes). It was assumed that all dogs not listed as desexed prior to admission, or did not have a desex date prior to their admission date were entire. All dogs made available for adoption were desexed, and if it was noted during the procedure that there was evidence of prior desexing, this was updated in the database. Dog size was allocated by comparing a dog's estimated mature height to a person of average height. Small dogs were defined as being less than knee height, medium dogs were approximately knee height, large dogs were thigh height and extra large dogs were approximately hip height.

For the purposes of this study, the sources of admission for each dog were organized under seven categories: owner surrender, stray, council admission, offspring of sheltered animals, euthanasia request, humane officer admission (employees of the RSPCA tasked with rescuing animals from situations where their welfare may be compromised), and other (Supplementary Materials, Table S1). Council admissions were mostly stray and some owner-surrendered dogs received by municipal councils and transferred to the RSPCA after a holding period of three to five days, or immediately under a pound management agreement (owner surrenders were transferred within $24 \mathrm{~h}$ ). Surrender reasons were organized under human or dog related reasons, and a series of categories and subcategories (Supplementary Materials, Table S2). The outcomes for the dogs entering RSPCA shelters were allocated into eight categories: reclaimed, adopted, euthanized, in shelter, in foster, unassisted death, transferred out and other (Supplementary Materials, Table S3). Off-site euthanasias and adoptions recorded by the RSPCA (for example, adoptions through pet shops) were included in the data. Dogs with a date for outcome in 2015 were assumed to be "in shelter" on the conclusion of 2014, unless their outcome was "in foster", whereby they were assumed to have already been "in foster" at the end of 2014. The RSPCA allocated reasons for euthanasia were organized into six categories, and a series of subcategories (Supplementary Materials, Table S4), for the purposes of this study.

Postcodes were recorded for where the animal was presented from ("lost/found postcode"), and for the person presenting the animal ("person postcode") (i.e., dogs which were presented as strays may have been found in a different postcode to the address of the finder). For the purposes of this study the "lost/found postcode" was used. If no "lost/found postcode" was recorded, the "person postcode" was used. No postcode was recorded for $348 \mathrm{dogs}$, and these animals were excluded from the postcode analysis. Intake per 1000 residents within a postcode was calculated using data from the ABS 2011 Census. The Socio-Economic Index For Areas (SEIFA Rank) was used to identify the relative socio-economic status for all postcodes from which two or more dogs were received [20]. The index is 
a relative measure. A low score indicates relatively greater disadvantage and a lack of advantage in the area, and a high score indicates a relative lack of disadvantage and greater advantage in the area.

Data excluded from analysis included repeat admissions $(n=1212)$, entries with missing age data $(n=770)$, dogs deceased prior to arrival $(n=82)$ and duplicate or erroneous data $(n=4)$. A total of 11,967 initial dog admissions were used for the analysis. For each analysis, entries with incomplete data relating to the categories studied were excluded.

\subsection{Statistical Analysis}

Most results were descriptive statistics but the null hypothesis that the proportions of annual admission numbers are the same in each month was statistically tested using the Describe (version 3.02) module in WinPepi version 11.50 [21]. To determine whether the proportions of annual adult admissions that occurred in each month differed from an equal proportion admitted each month, overall goodness-of-fit was assessed using Pearson's chi-square goodness-of-fit test [22]. For the proportions of annual admissions that occurred in each month, 95\% confidence intervals were estimated [23]. Chi-square goodness-of-fit tests were also used to compare the observed frequency in each month with the combined observed frequencies of the other categories [24] to determine which months had significantly higher or lower proportions admitted. Sidak-corrected $p$-values were used. The same analyses were performed for puppy admissions. For all analyses, values of $p<0.05$ were considered significant.

\section{Results}

\subsection{Source of Admission}

Of the dogs included in the analysis $(11,967)$ that entered RSPCA Queensland shelters in 2014, most were strays presented to the RSPCA by members of the public (24\%), or were council admissions (34\%) (Table 1). Just under $20 \%$ of all dogs admitted were surrendered by owners directly to the RSPCA. The majority of adult admissions were council admissions (39\%), whereas the majority of puppy ( $\leq 6$ months) admissions were owner surrenders (32\%). A similar proportion of adults and puppies were admitted as strays.

Table 1. Summary of age group (adult $>6$ months and puppy $\leq 6$ months), sex and admission source of 11,949 dogs processed through RSPCA Queensland shelters in 2014.

\begin{tabular}{llll|ll|ll}
\hline \multirow{2}{*}{ Admission Source } & All Dogs & & Female & & Male & \\
\cline { 2 - 7 } & Total & Adult & Puppy & Adult & Puppy & Adult & Puppy \\
\hline Council & $34 \%(4087)$ & $39 \%(3471)$ & $20 \%(616)$ & $37 \%(1483)$ & $19 \%(297)$ & $41 \%(1988)$ & $21 \%(319)$ \\
Stray & $24 \%(2910)$ & $24 \%(2130)$ & $25 \%(780)$ & $24 \%(979)$ & $24 \%(375)$ & $24 \%(1151)$ & $26 \%(405)$ \\
Owner Surrender & $19 \%(2279)$ & $15 \%(1310)$ & $32 \%(969)$ & $15 \%(602)$ & $32 \%(488)$ & $15 \%(708)$ & $31 \%(481)$ \\
Humane Officer & $6 \%(749)$ & $6 \%(567)$ & $6 \%(182)$ & $7 \%(266)$ & $5 \%(83)$ & $6 \%(301)$ & $6 \%(99)$ \\
Euthanasia Request & $4 \%(469)$ & $5 \%(456)$ & $<1 \%(13)$ & $5 \%(219)$ & $<1 \%(7)$ & $5 \%(237)$ & $<1 \%(6)$ \\
Offspring & $1 \%(128)$ & $<1 \%(5)$ & $4 \%(123)$ & $<1 \%(4)$ & $4 \%(64)$ & $<1 \%(1)$ & $4 \%(59)$ \\
Other & $11 \%(1327)$ & $11 \%(935)$ & $13 \%(392)$ & $11 \%(445)$ & $14 \%(217)$ & $10 \%(490)$ & $11 \%(175)$ \\
\hline Total & 11,949 & 8874 & 3075 & 3998 & 1531 & 4876 & 1544 \\
\hline
\end{tabular}

Eighteen dogs were excluded from the analysis because sex was not recorded.

\subsection{Age, Sex and Desex Status}

The majority $(74 \%, 8874)$ of dog admissions were adults older than six months and $26 \%$ were puppies $\leq 6$ months of age (Figure 1 ). The biggest age category ( $33 \%$ of admissions) were mature adults $>2$ years to seven years. Similar numbers of juveniles (7-12 months), young adults (13-24 months) and senior adults ( $>7$ years) were admitted. More males (54\%) were admitted than females (46\%) and there were $10 \%$ more adult males than adult females. In puppies, there was minimal difference 
between males than females $(0.4 \%)$. The difference in the ratio of males to females increased as dog age increased up to seven years with a 13\% difference between mature adult males and females (Figure 1).

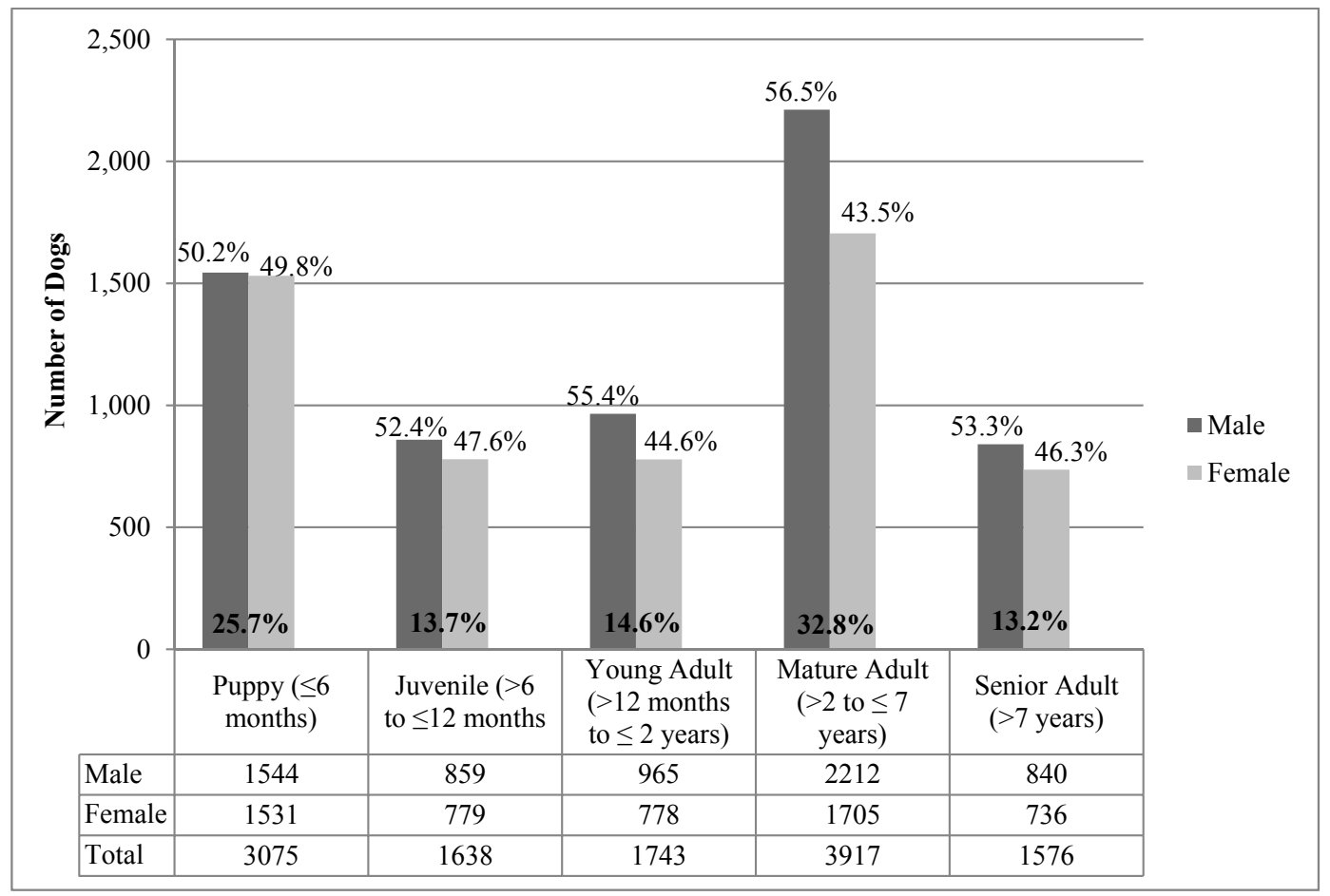

Figure 1. Summary of age groups and sex for 11,949 dogs admitted to RSPCA Queensland shelters in 2014 (18 dogs were excluded from the analysis because sex was not recorded).

More adult males were admitted as council admissions (41\%) than adult females (37\%), whereas, for other admission sources, the ratio of adult males to adult females was very similar (Table 1). For puppies for all sources of admissions, the ratio of males to females was similar. Only $14 \%$ of dogs were listed as desexed on entry, and the remaining $86 \%$ were presumed to be entire. Just $2 \%$ of puppies were known to be desexed on admission, whilst $18 \%$ of adult dogs were known to be desexed on admission. Similar ratios of males and females were known to be desexed prior to arrival, with a slightly higher percentage of females desexed (Table 2). The same proportion of male and female puppies were desexed. The proportion of dogs desexed prior to admission increased as age increased (Table 2) with the exception of senior adults (15\%). One quarter of mature adults (two to seven years) were desexed prior to entry. The admission group with the greatest proportion of desexed animals was owner surrenders (21\%).

Table 2. Summary of desex status for 11,967 dogs admitted to RSPCA Queensland shelters in 2014.

\begin{tabular}{|c|c|c|}
\hline \multicolumn{2}{|c|}{ Admission Groups } & Desexed \\
\hline Adults & $\begin{array}{c}\text { Female } \\
\text { Male } \\
\text { Total }\end{array}$ & $\begin{array}{c}19 \%(765) \\
18 \%(878) \\
18 \%(1643)\end{array}$ \\
\hline Puppies & $\begin{array}{c}\text { Female } \\
\text { Male } \\
\text { Total }\end{array}$ & $\begin{array}{l}1 \%(17) \\
1 \%(24) \\
2 \%(41)\end{array}$ \\
\hline \multicolumn{2}{|c|}{$\begin{array}{l}\text { Puppy } \\
\text { Juvenile }\end{array}$} & $\begin{array}{c}1 \%(41) \\
10 \%(161) \\
21 \%(825)\end{array}$ \\
\hline
\end{tabular}


Table 2. Cont.

\begin{tabular}{cc}
\hline Admission Groups & Desexed \\
\hline Mature Adult & $25 \%(394)$ \\
Senior Adult & $15 \%(263)$ \\
\hline Council & $15 \%(603)$ \\
Owner Surrender & $21 \%(482)$ \\
Stray & $10 \%(294)$ \\
Other & $15 \%(204)$ \\
Humane Officer & $7 \%(52)$ \\
Euthanasia Request & $10 \%(48)$ \\
Offspring & $1 \%(1)$ \\
\hline Total & $\mathbf{1 4 \% ( \mathbf { 1 6 8 4 } )}$ \\
\hline
\end{tabular}

Eighteen dogs were excluded from the analysis because sex was not recorded.

\subsection{Postcode of Source}

When shelter intakes were compared to the human population of the "lost/found" postcode, the five greatest intakes per 1000 residents occurred in Kingaroy, Caboolture, Gympie, Morayfield and Burdell, and their intakes ranged from 15-21/1000 residents (intakes of less than 50 dogs per postcode were excluded from this analysis) (Table 3). However, the five greatest total intakes were from Toowoomba, Caboolture, Gympie, Townsville and Dakabin. Two of the top five total dog admissions postcodes were also within the top five intakes per 1000 residents (4510 and 4570), whereas the region with the greatest number of admissions only had an intake of eight dogs per 1000 residents. Suburbs and towns included within each postcode are recorded in the Supplementary Materials (Table S5). The Socio-Economic Index For Areas (SEIFA) Rank for postcodes receiving two or more dogs ranged from 419 to 5 (median index 242, lower quartile 126). Of the five postcodes with the highest intakes per 1000 residents and total intakes of at least $50 \mathrm{dogs}$, three of the five had scores of around or below the lower quartile (median index 94), indicating relatively greater disadvantage and a lack of advantage in the area. Notably, the 17 postcodes with scores of $>400$, all but two had intakes of $<1 \mathrm{dog} / 1000$ residents and the other two had intakes of 1.4 and $2.1 \mathrm{dogs} / 1000$ residents. 
Table 3. Shelter intake according to source postcode.

\begin{tabular}{|c|c|c|c|c|c|c|c|c|c|}
\hline \multicolumn{5}{|c|}{ Twenty Greatest Intakes by Dog Admissions per 1000 Residents } & \multicolumn{5}{|c|}{ Twenty Greatest Intakes by Total Dog Admissions } \\
\hline Postcode & Population & Dog Admissions & Intake per 1000 Residents & SEIFA Rank & Postcode & Population & Dog Admissions & Intake per 1000 Residents & SEIFA Rank \\
\hline 4610 & 14,486 & 301 & 20.78 & 129 & 4350 & 102,244 & 819 & 8.01 & 207 \\
\hline 4510 & 42,206 & 725 & 17.18 & 62 & 4510 & 42,206 & 725 & 17.18 & 62 \\
\hline 4570 & 39,094 & 670 & 17.14 & 68 & 4570 & 39,094 & 670 & 17.14 & 68 \\
\hline 4506 & 19,702 & 306 & 15.53 & 165 & 4814 & 44,389 & 506 & 11.40 & 287 \\
\hline 4818 & 20,307 & 313 & 15.41 & 310 & 4503 & 34,305 & 418 & 12.18 & 262 \\
\hline 4810 & 21,523 & 328 & 15.24 & 289 & 4670 & 77,159 & 365 & 4.73 & 82 \\
\hline 4508 & 19,673 & 292 & 14.84 & 37 & 4810 & 21,523 & 328 & 15.24 & 289 \\
\hline 4502 & 8499 & 117 & 13.77 & 313 & 4818 & 20,307 & 313 & 15.41 & 310 \\
\hline 4815 & 20,523 & 275 & 13.40 & 169 & 4506 & 19,702 & 306 & 15.53 & 165 \\
\hline 4021 & 9929 & 131 & 13.19 & 94 & 4610 & 14,486 & 301 & 20.78 & 129 \\
\hline 4503 & 34,305 & 418 & 12.18 & 262 & 4508 & 19,673 & 292 & 14.84 & 37 \\
\hline 4580 & 4513 & 52 & 11.52 & 25 & 4815 & 20,523 & 275 & 13.40 & 169 \\
\hline 4814 & 44,389 & 506 & 11.40 & 287 & 4500 & 37,629 & 270 & 7.18 & 338 \\
\hline 4501 & 5356 & 58 & 10.83 & 125 & 4817 & 29,741 & 234 & 7.87 & 309 \\
\hline 4504 & 16,224 & 172 & 10.60 & 72 & 4300 & 45,133 & 203 & 4.50 & 232 \\
\hline 4505 & 18,726 & 197 & 10.52 & 271 & 4505 & 18,726 & 197 & 10.52 & 271 \\
\hline 4562 & 7193 & 67 & 9.31 & 330 & 4504 & 16,224 & 172 & 10.60 & 72 \\
\hline 4019 & 19,007 & 164 & 8.63 & 110 & 4019 & 19,007 & 164 & 8.63 & 110 \\
\hline 4076 & 6794 & 56 & 8.24 & 87 & 4680 & 50,831 & 154 & 3.03 & 303 \\
\hline 4615 & 6859 & 56 & 8.16 & 27 & 4812 & 19,476 & 134 & 6.88 & 176 \\
\hline
\end{tabular}

The Socio-Economic Index For Areas (SEIFA) rank is a relative measure of socio economic advantage and disadvantage. A low score indicates a relatively greater disadvantage and a lack of advantage, than a high score. Rank for postcodes receiving two or more dogs ranged from 419 to 5 (median index 242, lower quartile 126). Postcodes were not recorded for 371 dogs; these were excluded from the analysis. 


\subsection{Size \& Primary Breed}

When grouped by size, most (45\%) were medium-sized, with similar proportions of large breed $(24 \%)$ and small breed $(21 \%)$, and only $10 \%$ were classed as extra large dogs (Figure 2). A greater percentage of adult dogs were small breed $(25 \%)$ than puppies $(10 \%)$, and a greater percentage of puppies were medium, large or extra large breed than adults.

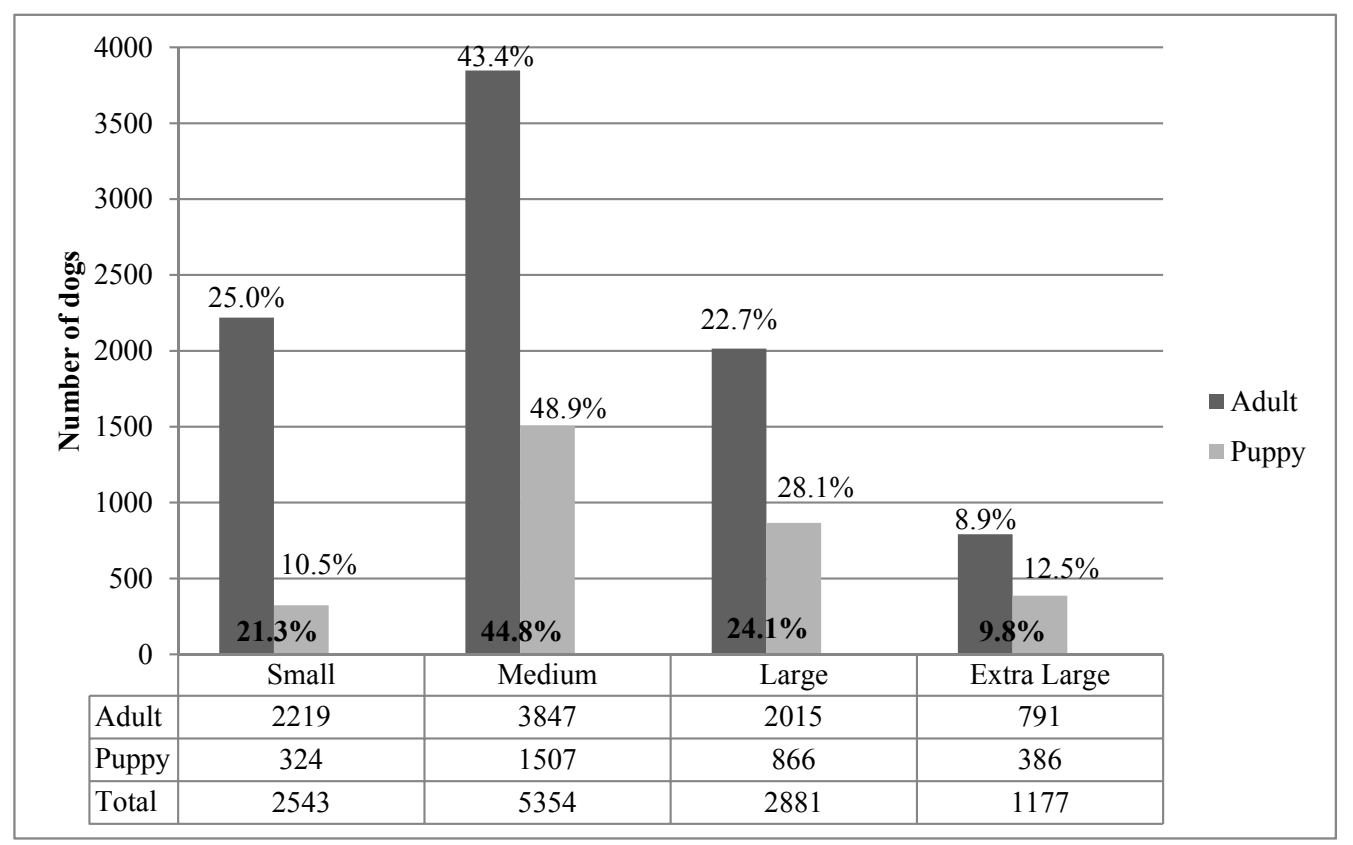

Figure 2. Estimated adult size (dog size was defined as follows: small dogs are less than average knee height, medium dogs are approximately knee height, large dogs are approximately thigh height and extra large dogs are hip height or taller) of 11,955 dogs admitted to RSPCA-QLD shelters in 2014 (12 dogs were excluded from the analysis because estimated mature size was not recorded).

The vast majority of dogs admitted were cross breeds, with just $8 \%$ of dogs listed as pure breeds. Of all dogs admitted, $83 \%$ were crossbreed or purebred dogs of 20 breeds (Table 4 ). The Staffordshire Bull Terrier was the most prevalent primary breed for both purebred (27\%) and crossbred (19\%) dogs, and was the primary breed for $20 \%$ of all dogs admitted (cross and pure breed). The five most common primary breeds for adults admitted were Staffordshire Bull Terrier, Australian Cattle Dog, Maltese Terrier, Labrador Retriever and Kelpie. The five most common breeds for puppies admitted were Staffordshire Bull Terrier, Bull Arab, Australian Cattle Dog, Kelpie and Border Collie. 
Table 4. Twenty most prevalent breeds of 11,967 dogs processed through RSPCA Queensland shelters in 2014.

\begin{tabular}{|c|c|c|c|c|c|c|c|}
\hline \multirow{2}{*}{ Primary Breed } & \multicolumn{3}{|c|}{ Total } & \multicolumn{2}{|c|}{ Adult } & \multicolumn{2}{|c|}{ Puppy } \\
\hline & Total & Pure Breed & Cross Breed & Pure Breed & Cross Breed & Pure Breed & Cross Breec \\
\hline Staffordshire Bull Terrier & $20 \%(2342)$ & $27 \%(255)$ & $19 \%(2087)$ & $27 \%(243)$ & $20 \%(1592)$ & $26 \%(12)$ & $16 \%(495)$ \\
\hline Australian Cattle Dog & $8 \%(968)$ & $2 \%(22)$ & $9 \%(946)$ & $2 \%(20)$ & $7 \%(577)$ & $4 \%(2)$ & $12 \%(369)$ \\
\hline Kelpie & $7 \%(825)$ & $2 \%(18)$ & $7 \%(807)$ & $1 \%(13)$ & $6 \%(491)$ & $11 \%(5)$ & $10 \%(316)$ \\
\hline Bull Arab & $7 \%(802)$ & $<1 \%(1)$ & $7 \%(801)$ & $<1 \%$ & $5 \%(430)$ & $0 \%(0)$ & $12 \%(371)$ \\
\hline Border Collie & $5 \%(598)$ & $6 \%(60)$ & $5 \%(538)$ & $7 \%(59)$ & $5 \%(372)$ & $2 \%(1)$ & $5 \%(166)$ \\
\hline Labrador Retriever & $5 \%(560)$ & $8 \%(79)$ & $4 \%(481)$ & $9 \%(78)$ & $5 \%(363)$ & $2 \%(1)$ & $4 \%(118)$ \\
\hline Maltese Terrier & $4 \%(507)$ & $2 \%(15)$ & $4 \%(492)$ & $1 \%(12)$ & $6 \%(444)$ & $7 \%(3)$ & $2 \%(48)$ \\
\hline Fox Terrier & $4 \%(429)$ & $2 \%(15)$ & $4 \%(414)$ & $2 \%(14)$ & $5 \%(364)$ & $2 \%(1)$ & $2 \%(50)$ \\
\hline Mastiff & $3 \%(371)$ & $<1 \%(1)$ & $3 \%(370)$ & $<1 \%(1)$ & $3 \%(252)$ & $0 \%(0)$ & $4 \%(118)$ \\
\hline Jack Russell Terrier & $3 \%(350)$ & $2 \%(21)$ & $3 \%(329)$ & $2 \%(21)$ & $3 \%(273)$ & $0 \%(0)$ & $2 \%(56)$ \\
\hline German Shepherd & $3 \%(309)$ & $4 \%(42)$ & $2 \%(267)$ & $4 \%(39)$ & $2 \%(178)$ & $7 \%(3)$ & $3 \%(89)$ \\
\hline Shih Tzu & $2 \%(269)$ & $1 \%(10)$ & $2 \%(259)$ & $1 \%(8)$ & $3 \%(215)$ & $4 \%(2)$ & $1 \%(44)$ \\
\hline Rottweiler & $2 \%(259)$ & $4 \%(35)$ & $2 \%(224)$ & $4 \%(32)$ & $2 \%(170)$ & $7 \%(3)$ & $2 \%(54)$ \\
\hline Chihuahua & $2 \%(229)$ & $1 \%(8)$ & $2 \%(221)$ & $1 \%(8)$ & $2 \%(182)$ & $0 \%(0)$ & $1 \%(39)$ \\
\hline Rhodesian Ridgeback & $2 \%(227)$ & $0 \%(0)$ & $2 \%(227)$ & $0 \%(0)$ & $2 \%(140)$ & $0 \%(0)$ & $3 \%(87)$ \\
\hline Great Dane & $2 \%(197)$ & $1 \%(5)$ & $2 \%(192)$ & $<1 \%(4)$ & $2 \%(133)$ & $2 \%(1)$ & $2 \%(59)$ \\
\hline Irish Wolfhound & $2 \%(193)$ & $0 \%(0)$ & 2\% (193) & $0 \%(0)$ & $2 \%(130)$ & $0 \%(0)$ & $2 \%(63)$ \\
\hline Bullmastiff & $1 \%(170)$ & $<1 \%(3)$ & $2 \%(167)$ & $<1 \%$ & $1 \%(100)$ & $0 \%(0)$ & $2 \%(67)$ \\
\hline Shar Pei & $1 \%(167)$ & $2 \%(17)$ & $1 \%(150)$ & $2 \%(16)$ & $1 \%(89)$ & $2 \%(1)$ & $2 \%(61)$ \\
\hline Boxer & $1 \%(167)$ & $2 \%(21)$ & $1 \%(146)$ & $2 \%(21)$ & $1 \%(103)$ & $0 \%(0)$ & $1 \%(43)$ \\
\hline Total Population $(11,967)$ & $100 \%(11,967)$ & $8 \%(943)$ & $92 \%(11,024)$ & $7 \%(897)$ & $67 \%(7986)$ & $<1 \%(46)$ & $25 \%$ \\
\hline
\end{tabular}

Percent of total population included in top 20 breeds $=83 \%$ (9939). 


\subsection{Date of Admission}

For the year 2014, within each of adults and puppies, the proportions of annual numbers of admissions differed by month ( $p<0.001$ for each). A significantly higher than expected proportion of the year's adult admissions occurred in January $(10.8 \% ; 95 \%$ CI 10.2-11.5\%; $p<0.001)$ and lower than expected proportions occurred in September $(7.2 \% ; 95 \%$ CI 6.7-7.8\%; $p=0.002)$, October $(7.1 \% ; 95 \%$ CI 6.6-7.7\%; $p<0.001)$ and November (7.2\%; 95\% CI 6.6-7.7\%; $p=0.001)$. A significantly higher than expected proportion of the year's puppy admissions occurred in January $(10.0 \%$; 95\% CI 8.9-11.1\%; $p=0.015)$ and September $(10.7 \%$; 95\% CI 9.6-11.8\%; $p<0.001)$ (Figure 3 and Table 5).

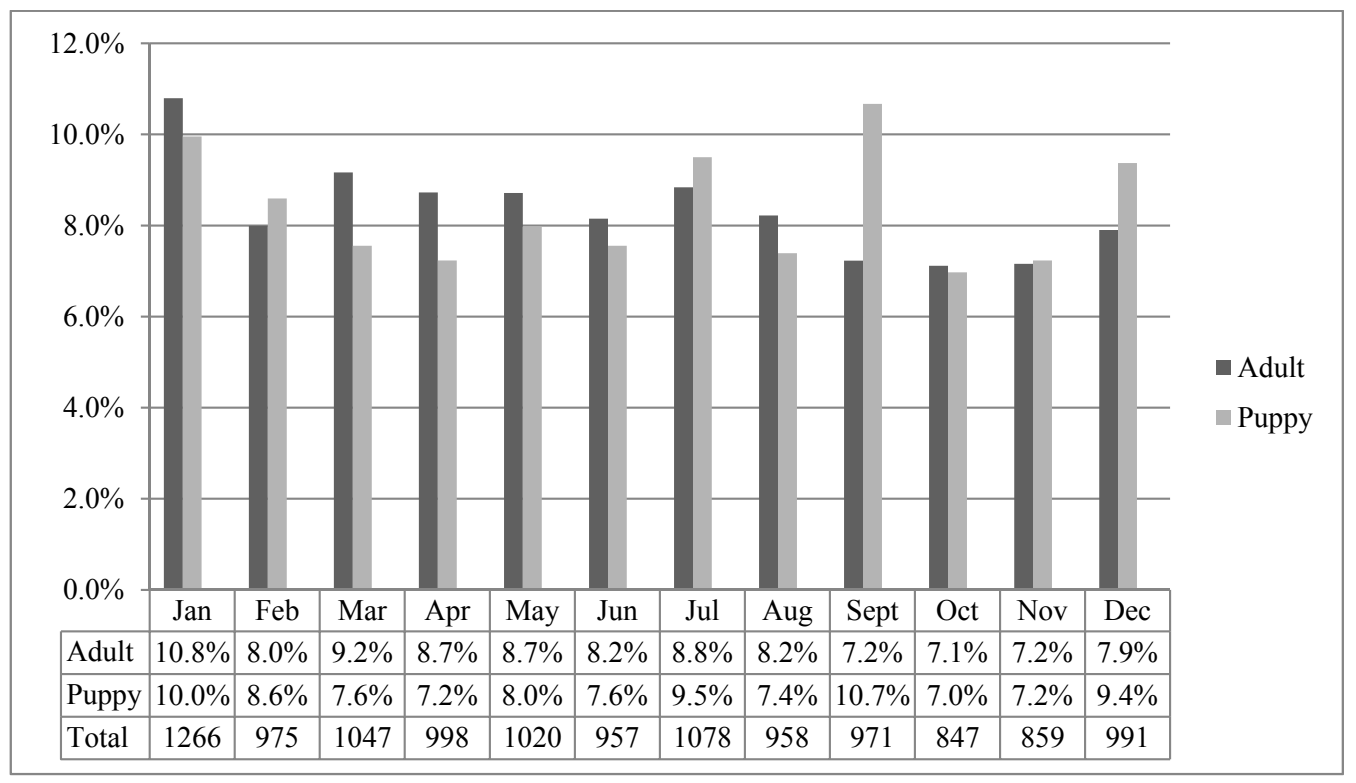

Figure 3. Numbers of admissions to RSPCA-QLD shelters in 2014 by month, and percentages of annual admissions by month within each of adult dogs $(n=8883)$ and puppies $(n=3084)$.

Table 5. Numbers and percentages of the annual admissions to RSPCA-QLD shelters by month in 2014 within each of adult dogs and puppies. $p$-values compare the observed frequency in each month with the combined observed frequencies of the other categories within columns.

\begin{tabular}{cccc|ccc}
\hline \multirow{2}{*}{ Month } & \multicolumn{3}{c|}{ Adults } & \multicolumn{3}{c}{ Puppies } \\
\cline { 2 - 7 } & Number (\%) & $\mathbf{9 5 \%}$ CI & $p$-Value & Number (\%) & $\mathbf{9 5 \% ~ C I ~}$ & $p$-Value \\
\hline January & $959(10.8)$ & $10.2-11.5 \%$ & $<0.001$ & $307(10.0)$ & $8.9-11.1 \%$ & 0.015 \\
February & $710(8.0)$ & $7.4-8.6 \%$ & 0.970 & $265(8.6)$ & $7.6-9.7 \%$ & 1.000 \\
March & $814(9.2)$ & $8.6-9.8 \%$ & 0.058 & $233(7.6)$ & $6.7-8.6 \%$ & 0.801 \\
April & $775(8.7)$ & $8.1-9.3 \%$ & 0.919 & $223(7.2)$ & $6.4-8.2 \%$ & 0.298 \\
May & $774(8.7)$ & $8.1-9.3 \%$ & 0.933 & $246(8.0)$ & $7.1-9.0 \%$ & 1.000 \\
June & $724(8.2)$ & $7.6-8.7 \%$ & 1.000 & $233(7.6)$ & $6.7-8.6 \%$ & 0.801 \\
July & $785(8.8)$ & $8.3-9.5 \%$ & 0.675 & $293(9.5)$ & $8.5-10.6 \%$ & 0.222 \\
August & $730(8.2)$ & $7.7-8.8 \%$ & 1.000 & $228(7.4)$ & $6.5-8.4 \%$ & 0.544 \\
September & $642(7.2)$ & $6.7-7.8 \%$ & 0.002 & $329(10.7)$ & $9.6-11.8 \%$ & $<0.001$ \\
October & $632(7.1)$ & $6.6-7.7 \%$ & $<0.001$ & $215(7.0)$ & $6.1-7.9 \%$ & 0.079 \\
November & $636(7.2)$ & $6.6-7.7 \%$ & 0.001 & $223(7.2)$ & $6.4-8.2 \%$ & 0.298 \\
December & $702(7.9)$ & $7.4-8.5 \%$ & 0.852 & $289(9.4)$ & $8.4-10.5 \%$ & 0.388 \\
\hline
\end{tabular}

Fewer dogs were admitted on weekends than on week days, with only $20 \%$ of adults and $16 \%$ of puppies admitted on weekends (Figure 4). Adult admissions remained approximately equal from Monday to Friday, with $15 \%$ to $17 \%$ of admissions occurring each day. A similar proportion of total puppy admissions (84\%) occurred on weekdays as adult admissions (80\%). 


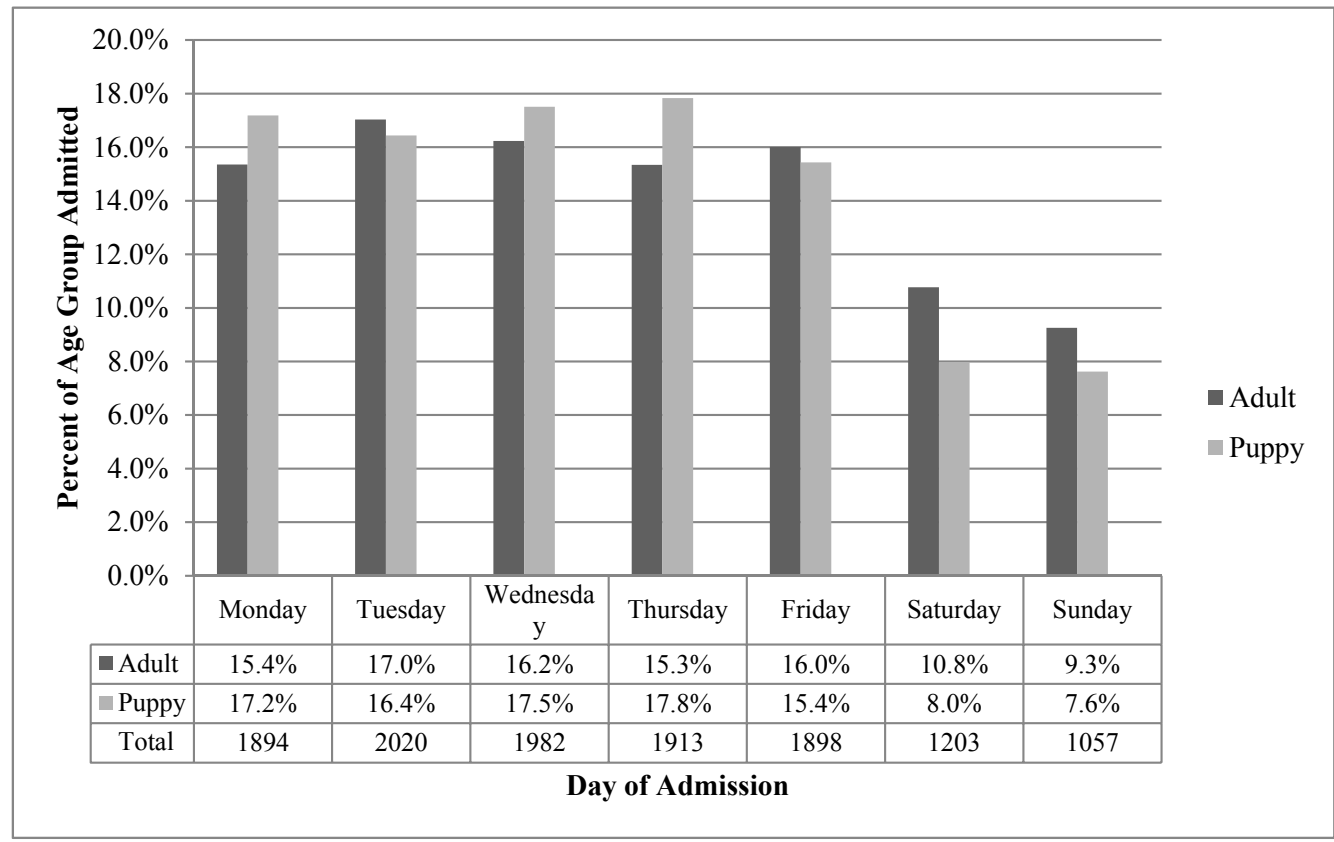

Figure 4. Summary of admission group and day of entry of 11,967 dogs processed through RSPCA-QLD shelters in 2014.

\subsection{Reason for Surrender}

Of the 2752 dogs admitted as owner surrenders or euthanasia requests, $68 \%$ had a reason for surrender recorded. The majority of these $(86 \%)$ were admitted for human-related reasons, and $14 \%$ were admitted for dog-related reasons (Table 6). Most surrendered dogs (40\%) were classified as unwanted pets. Puppies contributed to the majority of these admissions, with $69 \%$ of puppy admissions and just $20 \%$ of adults surrendered because they were unwanted. The majority of unwanted adult dogs were surrendered because their owners felt they made a poor decision $(41 \%)$, whereas the majority of unwanted puppies were surrendered because too many dogs were owned $(81 \%)$ (this category included unwanted litters). The majority of adult dog surrenders were due to a change in circumstances $(29 \%)$, the most frequent of which was the owners moving or travelling $(60 \%)$. The most common dog-related reason for surrender was behavioral $(13 \%)$ with $35 \%(n=88)$ of these surrendered for aggressive or predatory behavior. Sixteen percent of all surrenders were due to owners being unable to afford care or treatment. 
Table 6. Reasons for surrender organized according to human or dog related factors for 1876 dogs surrendered to RSPCA-QLD shelters in 2014 (a surrender reason was not recorded for 876 surrendered dogs, and therefore were not included in the analysis).

\begin{tabular}{|c|c|c|c|c|c|}
\hline Human/Dog Related Factor & Surrender Reason Category & Surrender Reason Sub Category & Total & Adult & Puppy \\
\hline \multirow{23}{*}{ Human } & & & $86 \%(1615)$ & $78 \%(860)$ & $98 \%(755)$ \\
\hline & \multirow{5}{*}{ Proportion of total surrendered as "unwanted" } & Total-Unwanted & $40 \%(751)$ & $20 \%(221)$ & $69 \%(530)$ \\
\hline & & Too many & $63 \%(473)$ & $21 \%(46)$ & $81 \%(427)$ \\
\hline & & Poor decision & $15 \%(116)$ & $41 \%(91)$ & $5 \%(25)$ \\
\hline & & Unspecified & $4 \%(31)$ & $12 \%(26)$ & $1 \%(5)$ \\
\hline & & Other & $17 \%(131)$ & $26 \%(58)$ & $14 \%(73)$ \\
\hline & \multirow[t]{2}{*}{ Changed circumstances } & Total-Changed circumstances & $20 \%(373)$ & $29 \%(326)$ & $6 \%(47)$ \\
\hline & & Moving/Travelling & $61 \%(227)$ & $60 \%(194)$ & $70 \%(33)$ \\
\hline & \multirow{3}{*}{$\begin{array}{l}\text { Proportion of total surrendered for } \\
\text { "changed circumstances" }\end{array}$} & Household dynamic & $23 \%(85)$ & $24 \%(79)$ & $13 \%(6)$ \\
\hline & & New Baby & $5 \%(17)$ & $5 \%(16)$ & $2 \%(1)$ \\
\hline & & Unspecified & $12 \%(44)$ & $11 \%(37)$ & $15 \%(7)$ \\
\hline & Financial & & $16 \%(304)$ & $14 \%(152)$ & $20 \%(152)$ \\
\hline & Accommodation & Total-Accommodation & $5 \%(100)$ & $7 \%(83)$ & $2 \%(17)$ \\
\hline & \multirow{5}{*}{$\begin{array}{l}\text { Proportion of total surrendered for } \\
\text { "Accommodation" reasons }\end{array}$} & Landlord will not allow ${ }^{1}$ & $60 \%(60)$ & $59 \%(49)$ & $65 \%(11)$ \\
\hline & & Yard too Small & $15 \%(15)$ & $14 \%(12)$ & $18 \%(3)$ \\
\hline & & Property unsuitable & $14 \%(14)$ & $13 \%(11)$ & $18 \%(3)$ \\
\hline & & Owner in care & $8 \%(8)$ & $10 \%(8)$ & $0 \%(0)$ \\
\hline & & Acquired without consent of household/landlord ${ }^{2}$ & $3 \%(3)$ & $4 \%(3)$ & $0 \%(0)$ \\
\hline & Owner Health & Total-Owner Health & $5 \%(86)$ & $7 \%(77)$ & $1 \%(9)$ \\
\hline & \multirow{3}{*}{$\begin{array}{c}\text { Proportion of total surrendered due to } \\
\text { "Owner Health" }\end{array}$} & Owner Ill & $66 \%(57)$ & $65 \%(50)$ & $78 \%(7)$ \\
\hline & & Owner Deceased & $20 \%(17)$ & $22 \%(17)$ & $0 \%(0)$ \\
\hline & & Owner Allergic & $14 \%(12)$ & $13 \%(10)$ & $22 \%(2)$ \\
\hline & Commercial $^{3}$ & & $<1 \%(1)$ & $<1 \%(1)$ & $0 \%(0)$ \\
\hline
\end{tabular}


Table 6. Cont

\begin{tabular}{|c|c|c|c|c|c|}
\hline Human/Dog Related Factor & Surrender Reason Category & Surrender Reason Sub Category & Total & Adult & Puppy \\
\hline \multirow{15}{*}{ Dog } & & & $14 \%(257)$ & $22 \%(245)$ & $2 \%(12)$ \\
\hline & Behavior & Total-Behavior & $13 \%(250)$ & $22 \%(239)$ & $1 \%(11)$ \\
\hline & & Escaping & $20 \%(49)$ & $20 \%(48)$ & $9 \%(1)$ \\
\hline & & Aggression-Animal & $17 \%(42)$ & $16 \%(39)$ & $27 \%(3)$ \\
\hline & & Aggressive-People & $13 \%(32)$ & $13 \%(30)$ & $18 \%(2)$ \\
\hline & & Aggressive-Human or Animal & $2 \%(4)$ & $2 \%(4)$ & $0 \%(0)$ \\
\hline & & Predatory behavior & $4 \%(10)$ & $4 \%(9)$ & $9 \%(1)$ \\
\hline & Proportion of total surrendered due to "Behavior" & Boisterous & $18 \%(45)$ & $18 \%(44)$ & $9 \%(1)$ \\
\hline & & Barking & $6 \%(14)$ & $5 \%(13)$ & $9 \%(1)$ \\
\hline & & Destructive & $4 \%(10)$ & $4 \%(10)$ & $0 \%(0)$ \\
\hline & & Fear & $4 \%(9)$ & $3 \%(7)$ & $18 \%(2)$ \\
\hline & & Inappropriate toileting & $1 \%(3)$ & $1 \%(3)$ & $0 \%(0)$ \\
\hline & & Other & $13 \%(32)$ & $13 \%(32)$ & $0 \%(0)$ \\
\hline & Dog size & & $<1 \%(6)$ & $1 \%(6)$ & $0 \%(0)$ \\
\hline & Dog Health & & $<1 \%(1)$ & $0 \%(0)$ & $<1 \%(1)$ \\
\hline \multirow[t]{2}{*}{ Other } & & & $<1 \%(4)$ & $<1 \%(4)$ & $0 \%(0)$ \\
\hline & 1 dogs surrendered & & $100 \%(1876)$ & $59 \%(1109)$ & $41 \%(767)$ \\
\hline
\end{tabular}

${ }^{1}$ Assumed to be relinquished prior to tenancy. ${ }^{2}$ Assumed to be relinquished after start of tenancy. ${ }^{3}$. Dog was described as "no good for racing", see Supplementary Materials, Table S2. 


\subsection{Outcomes}

The majority of dogs admitted into RSPCA QLD shelters in 2014 were adopted (43\%), and 32\% of dogs were reclaimed. Just $14 \%$ of dogs were euthanized and $7 \%$ were still residing in the shelter or in foster care at the conclusion of 2014 (Table 7). The most common outcome for puppies was adoption $(71 \%)$, whereas adults were most frequently reclaimed (39\%). Just $10 \%$ of puppies were reclaimed. A greater percentage of adults were euthanized than puppies $(17 \%$ of adults and $5 \%$ of puppies). Adoption was the second most frequent outcome for adult dogs, with $34 \%$ of all adults adopted, $55 \%$ of unclaimed adults adopted and $63 \%$ of surrendered adults adopted. Of the $68 \%$ of dogs that were not reclaimed, $79 \%$ of puppies were adopted and just $5 \%$ of puppies were euthanized, whereas $27 \%$ of unclaimed adults were euthanized.

Table 7. Summary of age group and outcome of 11,967 dogs processed through RSPCA Queensland shelters in 2014.

\begin{tabular}{lccc}
\hline Outcome & Total & Adult & Puppy \\
\hline Reclaimed & $32 \%(3775)$ & $39 \%(3473)$ & $10 \%(302)$ \\
Adopted & $43 \%(5183)$ & $34 \%(2989)$ & $71 \%(2194)$ \\
Euthanized & $14 \%(1619)$ & $17 \%(1471)$ & $5 \%(148)$ \\
In Shelter & $7 \%(804)$ & $6 \%(517)$ & $9 \%(287)$ \\
Transfer Out & $4 \%(440)$ & $4 \%(360)$ & $3 \%(80)$ \\
Unassisted death & $1 \%(89)$ & $<1 \%(31)$ & $2 \%(58)$ \\
In Foster & $<1 \%(20)$ & $<1 \%(15)$ & $<1 \%(5)$ \\
Other & $<1 \%(37)$ & $<1 \%(27)$ & $<1 \%(10)$ \\
\hline Total dogs unclaimed & $68 \%(8192)$ & $61 \%(5410)$ & $90 \%(2782)$ \\
Unclaimed dogs adopted & $63 \%(5183)$ & $55 \%(2989)$ & $79 \%(2194)$ \\
Unclaimed dogs euthanized & $20 \%(1619)$ & $27 \%(1471)$ & $5 \%(148)$ \\
\hline Surrendered dogs adopted & $72 \%(1580)$ & $63 \%(780)$ & $83 \%(800)$ \\
Surrendered dogs euthanized & $14 \%(317)$ & $22 \%(271)$ & $5 \%(46)$ \\
\hline Total & $\mathbf{1 1 , 9 6 7}$ & $\mathbf{8 8 8 3}$ & $\mathbf{3 0 8 4}$ \\
\hline
\end{tabular}

A reason for euthanasia was recorded for all 1619 dogs euthanized in RSPCA-QLD shelters in 2014. More than half (53\%) of all euthanasias were for behavioral reasons with $80 \%$ of these euthanized for aggressive behavior (Table 8). Approximately $45 \%$ of adult euthanasias were for aggressive behavior, compared to just $15 \%$ of puppy euthanasias. Most puppy euthanasias were based on health $(67 \%)$, and $45 \%$ of these were euthanized for parvovirus infection or contact with a parvovirus infected animal. Owner requested euthanasia was the second most common reason for adult euthanasia (21\%), but a similar proportion of adult euthanasias were due to health (19\%) (most commonly musculoskeletal or neoplastic diseases). Just $5 \%$ of puppy euthanasias occurred as a result of an owner's request.

Table 8. Reasons for euthanasia for 1619 dogs euthanized in RSPCA-QLD shelters in 2014.

\begin{tabular}{llccc}
\hline Euthanasia Reason Category & Euthanasia Reason Sub-Category & Total & Adult & Puppy \\
\hline Behavior & Total-Behavior & $\mathbf{5 3 \% ( 8 5 5 )}$ & $\mathbf{5 6 \% ( 8 2 1 )}$ & $\mathbf{2 3 \% ( 3 4 )}$ \\
\hline & Aggression-Directed towards Animals & $50 \%(428)$ & $50 \%(413)$ & $44 \%(15)$ \\
& Aggression-Target not defined & $16 \%(133)$ & $16 \%(128)$ & $15 \%(5)$ \\
Proportion of total euthanized for & Aggression-Directed towards humans & $15 \%(128)$ & $15 \%(126)$ & $6 \%(2)$ \\
behavioral reasons: & Personality-Fearful & $16 \%(134)$ & $15 \%(125)$ & $26 \%(9)$ \\
& Personality-Other & $2 \%(15)$ & $2 \%(13)$ & $6 \%(2)$ \\
& Escaping & $2 \%(17)$ & $2 \%(16)$ & $3 \%(1)$ \\
\hline
\end{tabular}


Table 8. Cont.

\begin{tabular}{|c|c|c|c|c|}
\hline Euthanasia Reason Category & Euthanasia Reason Sub-Category & Total & Adult & Puppy \\
\hline Health & Total-Health & $23 \%(378)$ & $19 \%(279)$ & $67 \%(99)$ \\
\hline \multirow{12}{*}{$\begin{array}{l}\text { Proportion of total euthanized for } \\
\text { health reasons: }\end{array}$} & Musculoskeletal & $18 \%(67)$ & $20 \%(55)$ & $12 \%(12)$ \\
\hline & Parvovirus & $17 \%(64)$ & $7 \%(19)$ & $45 \%(45)$ \\
\hline & Cancer & $12 \%(47)$ & $17 \%(47)$ & $0 \%(0)$ \\
\hline & Neurological & $5 \%(19)$ & $5 \%(15)$ & $4 \%(4)$ \\
\hline & Heartworm & $4 \%(15)$ & $5 \%(15)$ & $0 \%(0)$ \\
\hline & Cardiac & $2 \%(8)$ & $2 \%(6)$ & $2 \%(2)$ \\
\hline & Ear & $2 \%(6)$ & $2 \%(6)$ & $0 \%(0)$ \\
\hline & Skin & $1 \%(5)$ & $2 \%(5)$ & $0 \%(0)$ \\
\hline & Tick Paralysis & $1 \%(4)$ & $1 \%(3)$ & $1 \%(1)$ \\
\hline & Ocular & $1 \%(3)$ & $1 \%(3)$ & $0 \%(0)$ \\
\hline & Dental & $1 \%(2)$ & $1 \%(2)$ & $0 \%(0)$ \\
\hline & Unspecified & $37 \%(138)$ & $37 \%(103)$ & $35 \%(35)$ \\
\hline Owner Requested & & $20 \%(323)$ & $21 \%(315)$ & $5 \%(8)$ \\
\hline Age & Total-Age & $3 \%(56)$ & $3 \%(50)$ & $4 \%(6)$ \\
\hline Proportion of total euthanized for & Too old & $89 \%(50)$ & $100 \%(50)$ & $0 \%(0)$ \\
\hline age reasons: & Too young & $11 \%(6)$ & $0 \%(0)$ & $100 \%(6)$ \\
\hline Restricted Breed & & $<1 \%(6)$ & $<1 \%(6)$ & $0 \%(0)$ \\
\hline Feral/wild dog ${ }^{1}$ & & $<1 \%(1)$ & $0 \%(0)$ & $1 \%(1)$ \\
\hline Total dogs euthanized & & $100 \%(1619)$ & 91\% (1471) & $9 \%(148)$ \\
\hline
\end{tabular}

${ }^{1}$ The dog in this category was a crossbred puppy, with dingo listed as its primary breed.

\section{Discussion}

\subsection{Source of Admission}

The concept of capacity for care is based on the premise that animal rescue organizations have a finite number of animals for which they can provide an acceptable level of care [25-27]. If intake exceeds this number, shelters may have to euthanize potentially adoptable animals to free up space. By reducing avoidable admissions and improving live release rates, shelters are better able to care for, and ensure positive outcomes for the animals in their care, which in turn reduces the number of admitted animals euthanized [28]. To reduce intake, communities need to find strategies to prevent avoidable admissions [27].

\subsubsection{Strays and Council Admissions}

The majority of dogs entering RSPCA shelters in 2014 were council admissions (34\%), most of which are stray dogs rather than owner surrendered animals [29]. Combined with the $24 \%$ of strays surrendered by members of the public, this implies that almost $60 \%$ of the dogs admitted into RSPCA-QLD shelters were strays. This is similar to a New Zealand study from 1999 to 2006 (52\% stray admissions) [30], but less than in a Victorian study from 2004 (83.8\% stray admissions) [13], and greater than in a UK study conducted in 2010 (25.8\% stray admissions) [14]. These differences likely reflect regional differences in containment of dogs, and admission policies between shelters. The differences also reflect how animals are classified on admission. Most council admissions were assumed to be strays, however, to more accurately estimate the magnitude of the stray population in our study, it is recommended that source of council admissions should also be recorded.

With strays and council admissions contributing to an overwhelming majority of dogs entering RSPCA-QLD shelters, strategies to prevent dogs from straying and increase their reclaim rates need to be considered. A recent study (2015) investigating the microchip data of dogs entering RSPCA-QLD shelters found that, despite mandatory microchipping of dogs in Queensland, just 28\% of stray dogs admitted into the shelters were microchipped, and, of those, 37\% had inaccurate details of the owner or were not registered with any database [31]. Reclaim rates were significantly higher for dogs with 
no microchip data problems ( $87 \%$ reclaimed), whereas there was increased length of stay in shelters, and decreased reclaim rates for dogs with microchip information problems (69\% reclaimed), or an absence of a microchip (37\% reclaimed) [31].

Reducing shelter intake is closely associated with reduced euthanasia of animals in the shelter $[18,19]$. An increase in both the percentage of microchipped dogs, and proportion with current owner contact details registered on a database, are required to reduce the numbers of stray and council admissions entering RSPCA shelters, and increase reclaim rates. This may include microchip database companies establishing a reminder system for owners to update contact details (SMS texts, emails, and letters), microchip awareness campaigns and discount microchipping targeted to locations overrepresented by stray admissions.

However, inherent limitations of the microchipping system are that finders of stray dogs are unable to access ownership information without a microchip reader. Visual identification with a tag displaying the owner's contact details facilitates the general public returning stray animals without requiring the assistance of organizations such as shelters, councils and veterinary practices. Research is warranted to determine if provision of free engraved ID tags is cost effective for municipalities and welfare agencies to reduce stray admissions. A centralized database for lost and found animals may also aid the general public, shelters and councils in reuniting stray animals with their owners.

The number of dogs presented to shelters as strays could also be reduced by changing the focus of animal control officers from impounding stray animals, to working with communities to prevent dogs from straying, and increasing compliance with registration (dog licensing) and identification [32]. Although it is often prohibited by municipal by-laws, some municipalities permit animal control officers to directly return stray dogs with identification to the owner, even if dog registration is not current [29]. This reduces stray admissions and is likely more cost effective for municipalities, given that some impounded dogs are not reclaimed because of cost $[1,33]$. Increasing the cost to municipal councils per dog managed by the RSPCA (and other animal welfare agencies with council contracts) may provide an incentive for municipalities to engage more proactively in increasing the number of dogs that can be returned directly to the owner.

\subsubsection{Owner Surrenders and Euthanasia Requests}

The proportion of owner surrenders and euthanasia requests admitted to RSPCA-QLD (23\%) was less than reported in a UK study (56\%) and a New Zealand study $(47 \%)[14,30]$. Most (19\%) of these RSPCA-QLD admissions were owner surrenders and only $4 \%$ were euthanasia requests, of which most were adult dogs. However, almost a third of puppy admissions were owner surrenders, which is similar to a Victorian study which found that $28 \%$ of puppies were admitted as owner surrenders [13]. Likewise, it was found that $15 \%$ of adult admissions were owner surrenders, compared to $14 \%$ reported in the Victorian study [13].

Interviews with owners who relinquished pets revealed that most owners are reluctant to surrender their pets, often prolonging the decision and opting for surrender as a last resort [34,35]. Many shelter organizations (including the RSPCA) offer resources aimed at assisting owners with their pet's problems. In particular, RSPCA-QLD require people surrendering their pets to attend an appointment prior to surrender, which provides an opportunity for shelter staff to explore reasons for surrender and provide advice, and gives owners time to reconsider their decision [29]. However, many owners are unaware of the availability of these resources [36]. Furthermore, they will often spend a considerable amount of time coming to a decision to surrender, and consequently, these efforts made at the point of surrender may have a reduced effect [34]. Increasing public awareness of the availability of these services earlier in the decision making process may aid in reducing admissions. For example, Pet Help Partners in New York implemented a phone-based support service where owners faced with surrendering their pets were provided with counseling and advice on finding alternatives to surrender [35]. It was found that retention rates were high for owners who contacted the organization prior to the point of surrender [35]. A similar approach would likely be effective 
in Australia, and pet retention strategies should be considered by municipalities as a service to pet owners, and likely represents better use of taxpayers' money than accepting all surrenders.

\subsection{Age, Sex and Desex Status}

Over a quarter (26\%) of admissions to RSPCA-QLD shelters were puppies, which is greater than the $10 \%$ reported by the Victorian study. Furthermore, just $18 \%$ of adult dogs entering RSPCA-QLD shelters were desexed, slightly less than reported in the 2004 Victorian study (23\%) [13], and considerably less than the average of $78 \%$ of owned dogs in Australia [2,37]. The proportion of dogs desexed prior to arrival increased as age increased (with the exception of senior dogs), however dogs reach puberty at an average age of six to nine months [38], so most dogs entering RSPCA-QLD shelters were desexed too late to prevent breeding. This indicates that a significant contributor to shelter admissions was likely to be poor desexing compliance, leading to excess puppies.

Studies have found significant declines in shelter intakes of cats occurred when subsidized desexing or trap neuter return programs were implemented [39,40], but the effectiveness of subsidized desexing programs has had a variable impact on shelter intake of dogs. A study conducted in 2011 in San Jose, California identified Chihuahuas as a significant contributor to shelter intake, and implemented a free desexing program targeted at Chihuahuas and Chihuahua crosses [40]. As a result, overall dog admissions decreased from seven dogs per 1000 humans to 6.1 in two years [40]. Similarly, a free desexing program in Austin, Texas targeted to zip codes with high shelter intake, low average income and scarcity of veterinary facilities slowed the increase in dog admissions, compared to intakes from other zip codes [39]. However, a subsidized desexing program primarily involving adopted shelter animals (which had not yet been sterilized) and low income families in New Hampshire did not significantly reduce intake or euthanasia of dogs, whilst cat intake and euthanasia declined significantly [39]. These findings suggest that subsidized desexing programs may be more effective for reducing shelter intakes of cats than for dogs (reflecting the higher proportion of incoming cats less than six months of age compared to dogs [17]) and subsidized desexing programs for dogs should be targeted for locations and breeds contributing to highest intakes.

\subsection{Postcode of Source}

The greatest overall number of dog admissions primarily occurred in large regional centers, and 12 of the top 20 postcodes all had admissions of $\geq 10$ dogs/1000 residents, which is above the average for Australia (9.3 dogs /1000 residents) [1]. A 2010 Australian study [41] found a significant relationship between owner demographics and pet confinement, and household income and obedience training attendance. A US study [42] found that owners relinquishing their animals were more likely to be less than 50 years old, and not have complete education beyond high school. Furthermore, in underserved neighborhoods within the USA (which are typically low socio-economic areas), approximately $87 \%$ of pets were found to be entire, compared to the national average of about $9 \%$ [33]. When people in underserved communities were provided with the access to spay/neuter resources, including cost assistance and transportation, the percentage of desexed pets in the community increased to national levels [33]. Socio-economic position, lifestyle and demographics play a role in pet relinquishment and straying [18]. This is consistent with our findings where three of the five postcodes with the highest intakes per 1000 residents had SEIFA ranks around or below the lower quartile, indicating relatively greater disadvantage and a lack of advantage in the area.

Desexing and identification programs, as well as programs which assist people to keep their pet, that are targeted to areas with a combination of high intake per capita and high total intake, are likely to have greatest effect in reducing intake and subsequent euthanasia. Many of these locations will be relatively disadvantaged, and require financial and other assistance to increase desexing and identification rates, and for owners to keep their pet rather than surrender it. 


\subsection{Primary Breed and Mature Size}

Of the 69,274 puppies registered by the Australian National Kennel Council (ANKC) in 2014, Staffordshire Bull Terriers (10\%), Labrador Retrievers (7\%), German Shepherds (5.2\%), Golden Retrievers (4.2\%) and Border Collies (3.9\%) were the top five breeds registered [43]. Similarly, Staffordshire Bull Terriers (20\%) and Border Collies (5\%) were among the five most prevalent breeds admitted to RSPCA-QLD shelters. Three of the five most prevalent primary breeds (Australian Cattle Dog, Kelpie and Border Collie) admitted into RSPCA-QLD shelters are classified as working dogs by the ANKC [43]. High intelligence and energy levels may contribute to a greater likelihood for these breeds to stray or have behavioral problems related to boredom, and be admitted into shelters [44].

According to a 2013 Australian pet ownership report, 50\% of owned dogs were crossbreds [37]. However, assuming that most planned litters are purebreds, the high prevalence of crossbred puppies $(98 \%)$ that entered RSPCA-QLD shelters suggests that there are still a significant number of unplanned litters occurring in the community. Additionally, a US study [42] found that crossbreds were at a greater risk of relinquishment. A free desexing program targeting the most prevalent breed entering shelters in San Jose, California resulted in an overall decrease in shelter admissions [40]. A similarly targeted subsidized desexing program focusing on Staffordshire Bull Terriers and their mixes ( $20 \%$ of admissions) in postcodes overrepresented by admissions may reduce dog admissions, and be cost-effective.

\subsection{Date of Admission}

Dogs generally have two estrus cycles a year, which commonly occur in Spring and Autumn [38]. Pregnancy lasts for two months and puppies are weaned from approximately six weeks old (i.e., summer to early autumn and winter to early spring) [38]. However, previous studies have indicated that there is little to no seasonal pattern in dog admissions, compared to the significant seasonal patterns noted in cat admissions $[30,39,45]$. Despite this, variations in puppy admissions were noted in our study, with significantly greater proportions admitted in September (Spring) and January (Summer).

A study of Victorian shelter admissions found an increase in total admission numbers in January and December, and suggested that this may be due to straying during thunderstorms or changes in human activity (e.g., school holidays). Our study also found that a significantly higher proportion of adult and puppies were admitted in January. Considering that the majority of adult and puppy admissions (63\% and $45 \%$, respectively) were strays or council admissions, thunderstorm activity and New Year's fireworks are possible explanations for our findings. Furthermore, the 2014 Queensland school holidays occurred in January, April, July, September/October and December [46]. This partially corresponds to the January and September peaks in puppy admissions, although it was noted that a significantly lower proportion of adult admissions occurred in September, October and November. In order to understand these admissions variations, further study into the reasons associated with admissions is required. A limitation of our study is the use of data from a single year. It is uncertain if these variances in monthly admission are repeatable over a number of years.

\subsection{Reason for Surrender}

The most frequently cited reasons for surrender included dog behavior (especially aggression and escaping), accommodation problems, and owner health and personal issues [13,34,47]. Similarly, our study found that adult dogs were most commonly surrendered due to changes in owner's circumstances $(29 \%)$, behavioral problems $(22 \%)$ and as unwanted animals $(20 \%)$, whereas puppies were most commonly surrendered as unwanted animals (69\%) (most due to overpopulation), and due to financial constraints (20\%).

Despite puppies contributing to $26 \%$ of the population of admitted dogs, they contributed to $41 \%$ of the surrendered population. This supports previous findings that risk of relinquishment decreases 
with length of ownership and age [42]. It is likely that the majority of the $56 \%$ of puppies surrendered due to "too many animals" were the result of unwanted litters, especially considering that $98 \%$ of puppies were crossbred. However, the second most frequent reason for surrender of puppies was financial considerations (20\%). It may be that some of these puppies were acquired impulsively, or at no or low cost. It has previously been reported that a lower level of education, and erroneous beliefs about desexing dogs and their reproductive cycles lead to a greater risk of relinquishment [42,47]. The positive link between low socio-economic status and dog admissions suggests that providing assistance with transport and access to low-cost and free desexing targeted to these underserviced areas is warranted [30]. A 2004 study of Victorian shelters found that $40 \%$ of owner-related reasons for surrender were due to accommodation or moving [13], whereas $20 \%$ of owner-related admissions in our study were due to moving or travelling, or accommodation problems. A US study into reasons for relinquishment found that $40 \%$ of owners who relinquished their animals for the reason of "moving" did so due to landlord conditions [48]. Strategies to change attitudes of landlords, body corporates and real-estate agents to pets, and change legislation regarding pets in rental properties are needed to reduce the number of pets surrendered. At the time of writing, several Australian states (including Queensland) were reviewing their Residential Tenancies Acts, and submissions have been made advocating the "no pets" clause should be deemed illegal [49].

A limitation of our study was that a single reason for surrender was recorded, whilst owner surrenders are often multifactorial [34,48]. To gain a greater understanding for the motivations behind owner relinquishment, shelters should consider providing owners with the option to provide more than one reason for surrender. A 2000 US study examining risk factors for relinquishment found that behaviors exhibited by relinquished animals were not unique to them, and were also exhibited by owned animals [42]. Additionally, another US study found that $29.5 \%$ of surrendered dogs were surrendered for non-aggressive behavioral reasons [47]. It is suggested that the risk of relinquishment depends on the owner's tolerance of these behaviors, expectations and knowledge [42], and a dog's perceived behavior is dependent on owner's prior experience [50]. More than $52 \%$ of owners relinquishing their animals for health and personal reasons believed that animals misbehaved out of spite [47]. Therefore, a proportion of the $22 \%$ of adult dogs admitted to RPCA-QLD shelters for behavioral reasons were likely due to a mismatch of the dog's behavior and the owner's expectations. Greater public accessibility to low-cost assistance with behavior problems, and greater awareness of RSPCA-QLD services for owners challenged with dog behavior problems are required to reduce behavior-related surrenders.

\subsection{Outcomes and Reasons for Euthanasia}

Fewer dogs were euthanized in our study (14\%) and a much greater proportion adopted (43\%) compared to a $2008 \mathrm{New}$ Zealand study (36\% adopted and $45 \%$ euthanized) [30], and a 2004 Victorian study (21\% adopted and $32 \%$ euthanized) [13]. Our study found that the majority of euthanized dogs were euthanized for aggression ( $42 \%$ ), and $23 \%$ for health reasons. In contrast, the Victorian study found that, of the dogs that were euthanized, $34 \%$ were due to health problems and $24 \%$ were due to aggression [13]. The greater proportion of adoptions in our study may be a result of the RSPCA's high profile adoption campaigns and marketing strategies, and initiatives to reduce intake, such as, surrender by appointment and their Animal Training and Behavior Centre. In Victoria, the majority of owners acquired their pets through breeders (50\%), pet shops $(11 \%)$ and friends and family $(11 \%)$ with just $14 \%$ of pets acquired from shelters [50]. To encourage the public to purchase animals through a shelter there needs to be greater public awareness of the quality of animals available for adoption, which are behavior and health checked, desexed, vaccinated and microchipped, and unlike many other sources, can be returned after a trial period if necessary. Many of the human-related reasons for surrender (such as landlord or council restrictions) may also prevent suitable potential owners from adopting a dog. Revising tenancy agreement legislation relating to "no-pets" clauses may also aid in increasing adoption rates. 
Future studies into the associations between dog characteristics (such as age, breed, sex and desex status), and their outcomes and reasons for euthanasia could be conducted using the results of our study. By understanding what dog-associated factors contribute to positive outcomes (reclaim or adoption), shelters such as the RSPCA can better target their programs to increase these outcomes.

\subsection{Study Limitations}

Our study only investigated dogs entering RSPCA-QLD shelters, the management of which may be different to other shelters within Queensland and Australia. Furthermore, there were limited data available on the characteristics of Queensland's owned dog population. Therefore, comparisons could not be made in regards to the prevalence of characteristics of the sheltered population compared to the owned population. Inconsistencies occurred in the shelters' data collection due to multiple people and shelters contributing to data entry. Furthermore, the RSPCA only records one reason for surrender and euthanasia, and potentially complex circumstances were not captured in the data. Research has shown that there is typically more than one reason associated with surrender $[36,47,51]$. There were also overlapping categories and the potential for differences in interpretation. For example, dogs that were surrendered because they were "acquired without consent of landlord/household" could potentially have been classified as "landlord won't allow". Definitions of dog age groups were not provided, and therefore varied depending on the personnel entering the data. Finally, variation exists between our results and previous studies, which may be due to date and geographical differences. This emphasizes the need for contemporary and targeted data to guide strategies to further reduce shelter admissions and euthanasia.

\section{Conclusions}

The proportion of desexed animals entering shelters is lower than for owned dogs in the general population, and puppy admissions contribute to a quarter of shelter admissions. Stray adult dogs and Staffordshire Bull Terrier crossbreds are major contributors to admissions. Admission numbers vary month to month with higher proportions of puppies and adults admitted in January. Further research is required to determine if variations are consistent over a number of years, and what they were associated with (e.g., breeding or changes in human activity). Puppies contribute to a considerable proportion of owner surrenders and the majority of surrenders are due to human-related factors, mostly too many animals or due to a change in circumstances. The most prevalent dog-related reasons for surrender are behavioral problems. The majority of dogs admitted are reclaimed or adopted, and aggressive behavior is the most common reason for euthanasia. Based on our study findings, the cost-effectiveness of programs to reduce intake and euthanasia, and increase reclaim or adoption rates should be evaluated. These could include low-cost or free desexing and identification programs targeted to breeds and locations associated with high total intake and intake per capita. Increased availability of support services to assist owners challenged with situations that increase the risk of surrender, such as problem behaviors, lack of pet-friendly accommodation, and other personal issues (including lack of finances for pet health care), will likely reduce admissions and subsequent euthanasia.

Supplementary Materials: The following are available online at www.mdpi.com/2076-2615/7/9/67/s1, Table S1. Original source of admission organized into seven categories, Table S2. Original surrender reasons organized into human or dog related factors, categories and subcategories, Table S3. Original outcomes organized into eight categories, Table S4. Original euthanasia reasons organized into categories and subcategories, Table S1. List of suburbs for postcodes listed in Table 3 [52].

Acknowledgments: The authors thank RSPCA Queensland and Sheila Collecott for their valuable assistance in providing the data and information of the management of shelters. Without their assistance, this report would not be possible. The authors would also like to thank Corinne Alberthson for advice on study design and methodology, and for her assistance with the descriptive statistics. The author also thank Maddie's Fund ${ }^{\circledR}$, Found Animals, and The Humane Society of the United States (HSUS) for their sponsorship of the article processing charges. 
Author Contributions: Megan Hemy and Jacquie Rand conceived and designed the study, with input from Mandy Paterson and John Morton. Megan Hemy analyzed the data and wrote the paper, with editing and content input from Jacquie Rand and Mandy Paterson. John Morton conducted the statistical analysis.

Conflicts of Interest: The authors declare no conflict of interest.

\section{References}

1. Chua, D.; Rand, J.; Morton, J. Surrendered and stray dogs in Australia-Estimation of numbers entering municipal pounds, shelters and rescue groups and their outcomes. Animals 2017, 7, 50. [CrossRef] [PubMed]

2. Animal Medicines Australia. Pet Ownership in Australia 2016. Available online: http: / / animalmedicinesaustralia.org.au/wp-content/uploads/2016/11/AMA_Pet-Ownership-in-Australia2016-Report_sml.pdf (accessed on 4 August 2017).

3. Royal Society for the Prevention of Cruelty to Animals. RSPCA National statistics 2013-2014. Available online: http://www.rspca.org.au/sites/default/files/website/The-facts/Statistics/RSPCA_AustraliaAnnual_Statistics_2013-2014.pdf (accessed on 17 February 2015).

4. Australian Bureau of Statistics. Australian Demographic Statistics, September 2014. Available online: http:/ / www.abs.gov.au/ausstats/abs@.nsf/mf/3101.0 (accessed on 15 April 2015).

5. Royal Society for the Prevention of Cruelty to Animals. Annual Report 2013/14; RSPCA Queensland Inc.: Bundaberg, QLD, Australia, 2014.

6. Royal Society for the Prevention of Cruelty to Animals. Consolidated Financial Report for the Year end 30 June 2014; RSPCA Queensland Inc.: Bundaberg, QLD, Australia, 2014.

7. Frommer, S.S.; Arluke, A. Loving them to death: Blame-Displacing strategies of animal shelter workers and surrenderers. Soc. Anim. 1999, 7, 1-16. [CrossRef]

8. Rohlf, V.; Bennett, P. Perpetration-induced traumatic stress in persons who euthanize nonhuman animals in surgeries, animal shelters, and laboratories. Soc. Anim. 2005, 13, 201-220. [CrossRef] [PubMed]

9. Baran, B.E.; Allen, J.A.; Rogelberg, S.G.; Spitzmüller, C.; DiGiacomo, N.A.; Webb, J.B.; Carter, N.T.; Clark, O.L.; Teeter, L.A.; Walker, A.G. Euthanasia-related strain and coping strategies in animal shelter employees. J. Am. Vet. Med. Assoc. 2009, 235, 83-88. [CrossRef] [PubMed]

10. Rogelberg, S.G.; Reeve, C.L.; Spitzmüller, C.; DiGiacomo, N.; Clark, O.L.; Teeter, L.; Walker, A.G.; Starling, P.G.; Carter, N.T. Impact of euthanasia rates, euthanasia practices, and human resource practices on employee turnover in animal shelters. J. Am. Vet. Med. Assoc. 2007, 230, 713-719. [CrossRef] [PubMed]

11. Reeve, C.L.; Rogelberg, S.G.; Spitzmüller, C.; Digiacomo, N. The caring-killing paradox: Euthanasia-related strain among animal-shelter workers. J. Appl. Soc. Psychol. 2005, 35, 119-143. [CrossRef]

12. Hennessy, M.B.; Voith, V.L.; Mazzei, S.J.; Buttram, J.; Miller, D.D.; Linden, F. Behavior and cortisol levels of dogs in a public animal shelter, and an exploration of the ability of these measures to predict problem behavior after adoption. Appl. Anim. Behav. Sci. 2001, 73, 217-233. [CrossRef]

13. Marston, L.C.; Bennett, P.C.; Coleman, G.J. What happens to shelter dogs? An analysis of data for 1 year from three Australian shelters. J. Appl. Anim. Welf. Sci. 2004, 7, 27-47. [CrossRef] [PubMed]

14. Stavisky, J.; Brennan, M.L.; Downes, M.; Dean, R. Demographics and economic burden of un-owned cats and dogs in the UK: Results of a 2010 census. BMC Vet. Res. 2012, 8, 163. [CrossRef] [PubMed]

15. Tuber, D.S.; Miller, D.D.; Caris, K.A.; Halter, R.; Linden, F.; Hennessy, M.B. Dogs in animal shelters: Problems, suggestions, and needed expertise. Psychol. Sci. 1999, 10, 379-386. [CrossRef]

16. Marston, L.C.; Bennett, P.C.; Coleman, G.J. What happens to shelter dogs? Part 2. Comparing three Melbourne welfare shelters for nonhuman animals. J. Appl. Anim. Welf. Sci. 2005, 8, 25-45. [CrossRef] [PubMed]

17. Alberthsen, C.; Rand, J.S.; Bennett, P.C.; Paterson, M.; Lawrie, M.; Morton, J.M. Cat admissions to RSPCA shelters in Queensland, Australia: Description of cats and risk factors for euthanasia after entry. Aust. Vet. J. 2013, 91, 35-42. [CrossRef] [PubMed]

18. Marsh, P. Replacing Myth with Math: Using Evidence-Based Programs to Eradicate Shelter Overpopulation; Town and Country Reprographics, Inc.: New Hampshire, NH, USA, 2010.

19. Lofflin, J. The euthanasia problem. Vet. Med. 2007, 102, 667-672.

20. Pink, B. Information Paper, An Introduction to Socio-Economic Indexes for Areas (SEIFA). Available online: http:/ / www.abs.gov.au/ausstats/abs@.nsf/mf/2039.0 (accessed on 6 January 2016). 
21. Abramson, J.H. Winpepi updated: Computer programs for epidemiologists, and their teaching potential. Epidemiol. Perspect. Innov. 2011. [CrossRef] [PubMed]

22. Zar, J. Biostatistical Analysis, 4th ed.; Prentice Hall: Upper Saddler River, NJ, USA, 1998.

23. Fleiss, J.; Levin, B.; Paik, M. Statistical Methods for Rates and Proportions, 3rd ed.; John Wiley \& Sons: Hoboken, NJ, USA, 2003.

24. Sheskin, D. Handbook of Parametric and Nonparametric Statistical Procedures, 4th ed.; Chapman and Hall: Boca Raton, FL, USA, 2007.

25. Newbury, S.; Blinn, M.K.; Bushby, P.A.; Cox, C.B.; Dinnage, J.D.; Griffin, B.; Hurley, K.F.; Isaza, N.; Jones, W.; Miller, L.; et al. Guidelines for Standards of Care in Animal Shelters. Available online: http://www. sheltervet.org/assets/docs/shelter-standards-oct2011-wforward.pdf (accessed on 15 April 2015).

26. Karsten, C. Understanding capacity for care (C4C) and optimizing length of stay (LOS). In Proceedings of the 6th National G2Z Summit, Gold Coast, Australia, 14-19 September 2015.

27. Miller, L.; Zawistowski, S. Shelter Medicine for Veterinarians and Staff, 2nd ed.; Wiley-Blackwell: Ames, IA, USA, 2012.

28. Karsten, C. Managed intake-A powerful tool to providing better care and outcomes. In Proceedings of the 6th National G2Z Summit, Gold Coast, Australia, 14-19 September 2015.

29. Paterson, M.; RSPCA Animal Care Campus Wacol, QLD, Australia. Personal Communication, 2015.

30. Rinzin, K.; Stevenson, M.A.; Probert, D.W.; Bird, R.G.; Jackson, R.; French, N.P.; Weir, J.A. Free-roaming and surrendered dogs and cats submitted to a humane shelter in Wellington, New Zealand, 1999-2006. N. Z. Vet. J. 2008, 56, 297-303. [CrossRef] [PubMed]

31. Lancaster, E.; Rand, J.; Collecott, S.; Paterson, M. Problems associated with the microchip data of stray dogs and cats entering RSPCA Queensland shelters. Animals 2015, 5, 332-348. [CrossRef] [PubMed]

32. Stosuy, T. Animal care and control in the 21st century. In National Animal Care and Control Association (NACA) News; National Animal Care and Control Association: Murrieta, CA, USA, 2015.

33. The Humane Society of the United States. Effective Animal Management for Building Humane Communities. Available online: https://www.animalsheltering.org/sites/default/files/content/CA_ Toolkit_DesignPolicy_FINAL.pdf (accessed on 30 July 2017).

34. DiGiacomo, N.; Arluke, A.; Patronek, G. Surrendering pets to shelters: The relinquisher's perspective. Anthrozoos 1998, 11, 41-51. [CrossRef]

35. Huegel, K. No place like home. In Animal Sheltering May/June; 2014; pp. 29-34.

36. Irvine, L. The problem of unwanted pets: A case study in how institutions "think" about clients' needs. Soc. Prob. 2003, 50, 550-566. [CrossRef]

37. Animal Health Alliance. Pet Ownership in Australia 2013. Available online: https://petsinaustralia.com.au/ wp-content/themes/_TBST-BusinessAccelerator-v3/library/Downloads/Pet-Ownership-in-Australia2013.pdf (accessed on 18 March 2015).

38. Greer, M.L. Canine Reproduction and Neonatology; CRC Press: Jackson, WY, USA, 2014.

39. White, S.C.; Jefferson, E.; Levy, J.K. Impact of publicly sponsored neutering programs on animal population dynamics at animal shelters: The New Hampshire and Austin experiences. J. Appl. Anim. Welf. Sci. 2010, 13, 191-212. [CrossRef] [PubMed]

40. Johnson, K.L.; Cicirelli, J. Study of the effect on shelter cat intakes and euthanasia from a shelter neuter return project of 10,080 cats from March 2010 to June 2014. Peer J. 2014, 2, e646. [CrossRef] [PubMed]

41. Rohlf, V.I.; Bennett, P.C.; Toukhsati, S.; Coleman, G. Why do even committed dog owners fail to comply with some responsible ownership practices? Anthrozoös 2010, 23, 143-155. [CrossRef]

42. New, J.C.; Salman, M.D.; King, M.; Scarlett, J.M.; Kass, P.H.; Hutchison, J.M. Characteristics of shelter-relinquished animals and their owners compared with animals and their owners in U.S. pet-owning households. J. Appl. Anim. Welf. Sci. 2000, 3, 179-201. [CrossRef]

43. Australian National Kennel Council Ltd. National Animal Registration Analysis 1986-2014. Available online: http:/ / ankc.org.au/media/4404/rego-stats-list_to-14.pdf (accessed on 5 October 2015).

44. Eken Asp, H.; Fikse, W.F.; Nilsson, K.; Strandberg, E. Breed differences in everyday behaviour of dogs. Appl. Anim. Behav. Sci. 2015, 169, 69-77. [CrossRef]

45. Alberthsen, C.L. The Australian Excess Cat Population: An Exploration of Cat Admissions and Outcomes to RSPCA Shelters. Ph.D. Thesis, University of Queensland, Brisbane, QLD, Australia, 18 November 2014. 
46. Department of Education Training and Employment. 2014 School Calendar. Available online: http:// education.qld.gov.au/public_media/calendar/pdf/2014-school-calendar.pdf (accessed on 18 October 2015).

47. Scarlett, J.M.; Salman, M.D.; New, J.J.G.; Kass, P.H. Reasons for relinquishment of companion animals in U.S. animal shelters: Selected health and personal issues. J. Appl. Anim. Welf. Sci. 1999, 2, 41-57. [CrossRef] [PubMed]

48. Shore, E.R.; Petersen, C.L.; Douglas, D.K. Moving as a reason for pet relinquishment: A closer look. J. Appl. Anim. Welf. Sci. 2003, 6, 39-52. [CrossRef] [PubMed]

49. Spervell, R. Victorian Renters May Soon Be Able to Welcome Pets into Their Home. Available online: https:/ / www.domain.com.au/news/victorian-renters-may-soon-be-able-to-welcome-pets-intotheir-home-20160722-gqbn5q/ (accessed on 31 July 2017).

50. Bennett, P.C.; Rohlf, V.I. Owner-companion dog interactions: Relationships between demographic variables, potentially problematic behaviours, training engagement and shared activities. Appl. Anim. Behav. Sci. 2007, 102, 65-84. [CrossRef]

51. Salman, M.D.; Hutchison, J.; Ruch-Gallie, R.; Kogan, L.; New, J.C.; Kass, P.H.; Scarlett, J.M. Behavioral reasons for relinquishment of dogs and cats to 12 shelters. Appl. Anim. Behav. Sci. 2000, 3, 93-106. [CrossRef]

52. Find a Postcode. Available online: http:/ / auspost.com.au/postcode (accessed on 23 February 2016).

(c) 2017 by the authors. Licensee MDPI, Basel, Switzerland. This article is an open access article distributed under the terms and conditions of the Creative Commons Attribution (CC BY) license (http:/ / creativecommons.org/licenses/by/4.0/). 